\title{
Motivações Toponímicas para Nomes de Aldeias dos Karipuna do Amapá
}

Toponymic motivations for village names from Karipuna do Amapá

Romário Duarte Sanches

Universidade do Estado do Amapá (UEAP) ${ }^{1}$

Resumo. $\mathrm{O}$ artigo visa identificar e classificar topônimos usados para nomear as aldeias pertencentes à etnia Karipuna do Amapá. Como suporte teórico adotou-se os postulados de Dick (1990) sobre a classificação de topônimos em taxes, conforme a natureza física ou antropo-cultural. E também o estudo de Tassinari (2003) a respeito da história e da cultura do povo Karipuna do Amapá. Os dados analisados correspondem à pesquisa de campo realizada em nove aldeias Karipuna com objetivo de coletar narrativas orais sobre a história das comunidades indígenas. A análise consistiu nos nomes das seguintes aldeias: Manga, Santa Isabel, Espírito Santo, Açaizal, Curipi, Kariá, Ahumã, Ariramba e Kunanã. Os resultados mostraram que as principais motivações para nomear as aldeias são de natureza física, do tipo fitotopônimos (Manga, Açaizal, Kariá, Ahumã e Kunanã), hidrotopônimos (Curipi) e zootopônimos (Ariramba). Em menor grau de motivação, registraram-se os de natureza antropo-cultural, é o caso dos hierotopônimos (Santa Isabel e Espírito Santo).

Palavras-chave: Toponímia; Léxico; Cultura; Karipuna do Amapá.

Abstract. The article aims to identify and classify toponyms used to name villages belonging to the Karipuna do Amapá ethnic group. As theoretical support, Dick's (1990) postulates on the classification of toponyms in taxes were adopted, according to the physical or anthropo-cultural nature. And also the study by Tassinari (2003) about the history and culture of the Karipuna people in Amapá. The analyzed data correspond to the field research carried out in nine Karipuna villages with the objective of collecting oral narratives about the history of the indigenous communities. The analysis consisted of the names of the following villages: Manga, Santa Isabel, Espírito Santo, Açaizal, Curipi, Kariá, Ahumã, Ariramba and Kunanã. The results showed that the main motivations for naming the villages are of a physical nature, of the phytotoponymous type (Manga, Açaizal, Kariá, Ahumã and Kunanã), hydrotoponyms (Curipi) and zootoponyms (Ariramba). In a lesser degree of motivation, those of an anthropo-cultural nature were registered, as is the case of hierotoponyms (Santa Isabel and Espírito Santo).

Keywords: Toponymy; Lexicon; Culture; Karipuna do Amapá.

\section{Introdução}

A língua é considerada um dos elementos mais importantes da cultura de um povo. Existe uma estreita relação entre o destino das línguas e o destino das culturas. De acordo com Melo (1981), a desagregação e o desaparecimento de uma língua para a formação de outras representam a desintegração ou o apagamento de uma cultura. Isto torna a língua o reflexo mais direto da cultura, ou seja, uma espécie de termômetro sensível que ajuda a medir a vitalidade e as oscilações da cultura.

Indissociável à língua encontra-se o léxico que constitui uma das principais formas de expressar e materializar o conhecimento dos seres humanos sobre o universo.

\footnotetext{
${ }^{1}$ Doutor em Letras (Linguística) pela Universidade Federal do Pará (UFPA) e Professor Substituto da Universidade do Estado do Amapá. Contato: romario.sanches@ueap.edu.br
} 
[...] ao dar nomes aos seres e objetos, o homem os classifica simultaneamente. Assim, a nomeação da realidade pode ser considerada como a etapa primeira do percurso científico do espírito humano de conhecimento do universo. Ao reunir os objetos em grupos, identificando semelhança e, inversamente, discriminando os traços distintivos que individualizam esses seres e objetos em entidades diferentes, o homem foi estruturando o mundo que o cerca, rotulando essas entidades discriminadas. Foi esse processo de nomeação que gerou o léxico das línguas naturais. (BIDERMAN, 2001, p. 13).

Deste modo, o léxico é concebido como testemunha da cultura. Um verdadeiro tesouro vocabular que engloba todos os conceitos linguísticos e não linguísticos e todos os referentes do mundo físico, além do universo cultural do presente e do passado da sociedade. Para Biderman (1992), esse tesouro lexical, formado por palavras (símbolos verbais da cultura), constitui um patrimônio da sociedade juntamente com outros símbolos da herança cultural. É no repertório lexical, isto é, no vocabulário que estão sintetizados a vida, os valores e as crenças de uma comunidade.

Assim, os topônimos - signos linguísticos ou unidades lexicais utilizadas para nomear acidentes geográficos físicos como rios, córregos, montanhas, e acidentes humanos como cidades, distritos, povoados - passam a ser entendidos como importantes testemunhas históricas da vida sociocultural de uma comunidade. Um estudo toponímico pode ajudar a obter importantes pistas sobre o universo sociocultural de grupos que habitam ou habitaram determinadas regiões.

Diante da relevância que os topônimos podem fornecer para compreensão sociocultural e linguística de um povo, este artigo visa identificar e classificar os topônimos usados para nomear as aldeias pertencentes à etnia Karipuna do Amapá - grupo indígena falante de Kheúol (língua crioula de base francesa) e que habita o extremo norte do Amapá. O texto está organizado da seguinte maneira: introdução; referencial bibliográfico (o estudo dos topônimos, os povos indígenas da região do Oiapoque e os Karipuna do Amapá); apresentação dos resultados e considerações finais.

\section{0 estudo dos topônimos}

A palavra Toponímia é de origem grega, topos significa "lugar" e onoma "nome". Atualmente, a Toponímia é considerada uma disciplina que estuda os nomes dos lugares e designativos geográficos: físicos, humanos, antrópicos ou culturais. Por sua vez, essa disciplina está inserida dentro de campo da Onomástica, isto é, segundo Dick (1990), a ciência que estuda os nomes próprios. Vale lembrar que a Onamástica divide-se em duas subáreas: Toponímia, estudo do nome próprio de lugares, e Antroponímia, estudo de nome próprio de pessoas.

O topônimo é considerado o objeto de estudo da Toponímia. Ao ser criado, o sentido adquirido estará sujeito às transformações ao longo do tempo ou até mesmo ao desaparecimento, pois depende da memória coletiva de um povo para se estabelecer. Isso faz com que o campo de estudo da Toponímia implique uma dupla dimensão: a do referente espacial geográfico (função toponímica) e a do referente temporal (memória toponímica).

Para realizar pesquisa toponímica é necessário relacionar este campo com outras áreas do conhecimento, por exemplo, com a História, Geografia, Antropologia, Linguística, etc. Isso significa em dizer que a Toponímia possui caráter interdisciplinar. 
Para Dick (1990), o topônimo consiste num signo linguístico em função onomástica e toponímica, utilizado para designar um espaço geográfico ou humano, ou seja, identificar acidentes geográficos (ou humanos). Com isso, o sentido estabelecido nessa relação configura-se como a primeira qualidade em que se infere o signo toponímico.

Ao escolher um nome de um determinado lugar, o sujeito apropria-se, muitas vezes, de aspectos próprios desse lugar que deseja nomear, como elementos da fauna e da flora, o que permite ter acesso ao modo de vida dos habitantes daquela região, seu modus vivendi.

Exercendo na toponímia a função de distinguir os acidentes geográficos na medida em que delimitam uma área da superfície terrestre e lhes conferem características específicas, os topônimos se apresentam, da mesma maneira que os antropônimos, como importantes fatores de comunicação, permitindo, de modo plausível, a referência da entidade por eles designada. Verdadeiros "testemunhos históricos" de fatos e ocorrências registradas nos mais diversos momentos da vida de uma população encerram em si, um valor que transcende ao próprio ato da nomeação: se a Toponímia situa-se como a crônica de um povo, gravando o presente para o conhecimento dessa projeção temporal. Chega, muitas vezes, a se espalhar além de seu foco originário, dilatando, consequentemente, as fronteiras políticas, e criando raízes em sítios distantes. Torna-se, pois, a reminiscência de um passado talvez esquecido, não fora a sua presença dinâmica (DICK, 1990, p. 22).

A pesquisa toponímica pode seguir uma linha documental ou de campo, tendo como suporte o método onomasiológico que prevê seleção, observação, documentação, classificação, análise e interpretação dos topônimos investigados.

Para Tavares e Isquerdo (2006), o estudo dos topônimos, na perspectiva linguística, pode ser realizado da seguinte maneira: análise de estratos linguísticos evidenciados pelos designativos, classificação taxionômica dos nomes, análise de taxes predominantes, discussão da motivação semântica dos nomes, estudo diacrônico referente às mudanças de nomes, análise da estrutura morfológica dos topônimos, etc.

Em relação aos componentes motivacionais, Dick (1990) elaborou um modelo classificatório que propõe o agrupamento dos topônimos em taxes, conforme suas principais características físicas ou antropo-cultural.

As taxionomias de natureza física fazem parte topônimos de ordem vegetal, animal, espacial, orográfica e hidrográfica. Estas são classificadas em astropônimos, cardinotopônimos, cromotopônimos, dimensiotopônimos, fitotopônomos, geomorfotopônimos, hidrotopônimos, litotopônimos, meteorotopônimos, morfotopônimos, zootopônimos. Abaixo o Quadro 1.

Quadro 1: Taxionomias de natureza física

\begin{tabular}{|l|l|}
\hline \multicolumn{1}{|c|}{ Tipo } & \multicolumn{1}{c|}{ Conceito } \\
\hline Astropônimos & Topônimos relativos aos corpos celestes em geral \\
\hline Cardinotopônimos & Topônimos relativos às posições geográficas em geral \\
\hline Cromotopônimos & Topônimos relativos à cor. \\
\hline Dimensiotopônimos & $\begin{array}{l}\text { Topônimos relativos às características dimensionais dos acidentes geográficos, como } \\
\text { extensão, comprimento, largura, grossura, altura, profundidade. }\end{array}$ \\
\hline Fitotopônomos & $\begin{array}{l}\text { Topônimos de índole vegetal, espontânea, em sua individualidade, em conjuntos da } \\
\text { mesma espécie, ou de espécies diferentes, além de formações não espontâneas. }\end{array}$ \\
\hline
\end{tabular}




\begin{tabular}{|l|l|}
\hline Geomorfotopônimos & Topônimos relativos às formas topográficas. \\
\hline Hidrotopônimos & Topônimos resultantes de acidentes hidrográficos em geral. \\
\hline Litotopônimos & $\begin{array}{l}\text { Topônimos de índole vegetal, relativos à constituição do solo, representados por } \\
\text { indivíduos, conjunto da mesma espécie, ou de espécies diferentes.. }\end{array}$ \\
\hline Meteorotopônimos & Topônimos relativos a fenômenos atmosféricos. \\
\hline Morfotopônimos & Topônimos que refletem o sentido de formas geográficas. \\
\hline Zootopônimos & $\begin{array}{l}\text { Topônimos de índole vegetal, representados por indivíduos domésticos, não } \\
\text { domésticos e da mesma espécie. }\end{array}$ \\
\hline
\end{tabular}

Fonte: Dick (1990).

No que tange às taxionomias de natureza antropo-cultural, estas estão ligadas aos topônimos que fazem referência ao universo psíquico-social do homem e são do tipo animotopônimos ou nootopônimos, antrotopônimos, axiotopônimos, corotopônimos, cronotopônimos, ecotopônimos, ergotopônimos, etnotopônimos, dirrematopônimos, hierotopônimos, hitoriotopônimos, hodotopônimos (odotopônimos), numerotopônimos, poliotopônimos, sociotopônimos e somatopônimos. Abaixo o Quadro 2.

Quadro 2: Taxionomias de natureza antropo-cultural

\begin{tabular}{|c|c|}
\hline Tipo & Conceito \\
\hline $\begin{array}{l}\text { Animotopônimos ou } \\
\text { Nootopônimos }\end{array}$ & $\begin{array}{l}\text { Topônimos relativos à vida psíquica, à cultura espiritual, abrangendo todos os } \\
\text { produtos do psiquismo humano. }\end{array}$ \\
\hline Antrotopônimos & Topônimos relativos aos nomes próprios individuais. \\
\hline Axiotopônimos & $\begin{array}{l}\text { Topônimos relativos aos títulos e dignidade de que se fazem acompanhar os nomes } \\
\text { próprios individuais. }\end{array}$ \\
\hline Corotopônimos & Topônimos relativos aos nomes de cidades, países, regiões, continentes. \\
\hline Cronotopônimos & $\begin{array}{l}\text { Topônimos que encerram indicadores cronológicos representados, em Toponímia, } \\
\text { pelos adjetivos novo/nova, velho/velha. }\end{array}$ \\
\hline Ecotopônimos & Topônimos relativos às habitações de um modo geral. \\
\hline Ergotopônimos & Topônimos relativos aos elementos da cultura material. \\
\hline Etnotopônimos & Topônimos relativos aos elementos étnicos, isolados ou não. \\
\hline Dirrematopônimos & Topônimos constituídos por frases ou enunciados linguísticos. \\
\hline Hierotopônimos & $\begin{array}{l}\text { Topônimos relativos aos nomes sagrados de diferentes crenças; às associações } \\
\text { religiosas; às efemeridades religiosas. }\end{array}$ \\
\hline Hitoriotopônimos & $\begin{array}{l}\text { Topônimos relativos aos movimentos de cunho histórico-social e aos seus membros, } \\
\text { assim como às datas correspondentes. }\end{array}$ \\
\hline $\begin{array}{l}\text { Hodotopônimos } \\
\text { (Odotopônimos) }\end{array}$ & Topônimos relativos às vias de comunicação rural ou urbana. \\
\hline Numerotopônimos & Topônimos relativos aos adjetivos numerais. \\
\hline Poliotopônimos & Topônimos constituídos pelos vocábulos vila, aldeia, cidade, povoação, arraial. \\
\hline Sociotopônimos & $\begin{array}{l}\text { Topônimos relativos às atividades profissionais, aos locais de trabalho e aos pontos de } \\
\text { encontro dos membros de uma comunidade. }\end{array}$ \\
\hline Somatopônimos & $\begin{array}{l}\text { Topônimos empregados em relação metafórica a partes do corpo humano ou do } \\
\text { animal. }\end{array}$ \\
\hline
\end{tabular}

Fonte: Dick (1990). 
A classificação expressa acima foi elaborada a partir da necessidade de consolidar bases teóricas válidas para o estudo dos topônimos, bem como para orientar os pesquisadores da área a respeito da ampla variedade de topônimos que pode ser encontrada, além de suas diferentes motivações. Cabe ressaltar que esta classificação pode ser expandida e aprimorada, conforme o surgimento de novos fenômenos.

Atualmente, os estudos toponímicos no Brasil tende a resgatar a história social e cultural contida nos nomes de lugares. É comum tomar como base a etimologia para reconstruir os significados e, posteriormente, traçar um panorama motivacional que explique os nomes dados a um determinado lugar.

De modo geral, o estudo toponímico busca examinar a relação entre língua e cultura representada, sobretudo no sistema lexical de uma determinada variedade linguística. O léxico possibilita perceber a vitalidade e a riqueza etnolinguística de um povo, além de contar suas transformações históricas e políticas.

\section{Povos indígenas da região do Oiapoque}

A presença indígena na região do Oiapoque, extremo norte do estado do Amapá, foi registrada e datada a partir do século XVI com base em documentos históricos (relatos) de estrangeiros que faziam parte de expedições missionárias, comerciais, armadas ou científicas. Assim, há registros de grupos indígenas de diferentes famílias linguísticas (Aruák, Karíb e Tupí-Guaraní) em contato com outros grupos de nacionalidades distintas (franceses, portugueses, holandeses, ingleses), além do contato com grupo de negros refugiados ou alforriados.

No século XVII, nos relatos de Mocquet (1617) e D’Avity (1643), há menção ao país dos Caripous, vizinho dos Caribes $^{2}$. Neste período, foram empreendidas as primeiras tentativas de estabelecimento das colônias europeias no Oiapoque (de origem inglesa, francesa e holandesa), mas que não deram certo, como a de Charles Leigh, de Harcourt, de Edward Harvey, de Padres Capuchinhos e outras (PARANHOS, 1945; HURAULT, 1972). Já na segunda metade deste século, os franceses fixaram-se definitivamente em Caiena, entretanto, o contingente indígena do litoral foi reduzido a 3.500 pessoas entre os rios Cachipour (atualmente denominado de Rio Cassiporé) e Maroni, entre os quais se verificou a existência de aproximadamente quarenta indígenas Yaos.

No final do século XVIII, registrou-se na região do Oiapoque o ataque abrupto da coroa portuguesa com objetivo de ocupar e despovoar o território até então contestado pela França. Trata-se do período no qual as "expedições portuguesas queimam aldeias, destroem estabelecimentos e casas de colonos franceses, invadem os territórios das missões, aprisionam a população indígena e deportam para o Amazonas" (TASSINARI, 2003, p. 93).

Em relação ao século XIX, os dados sobre as populações indígenas do Oiapoque estão restritos a relatos feitos pelos viajantes ${ }^{3}$ que buscavam estabelecer contato com os Wajãpi, Wayana e Émerillon. Durante este século, vários grupos indígenas vindos do território contestado e de outros

\footnotetext{
2 A atual Guiana era designada pelos autores da segunda metade do século XVII por "país dos Caribes" ou "Caribana" (TASSINARI, 2003, p. 83).

${ }^{3}$ Hurault (1972).
} 
lugares do Brasil, passaram pela região do Oiapoque, alguns dizimados pelas epidemias e outros pela exploração da mão-de-obra.

Percebe-se que no decorrer dos séculos o contato entre os diferentes grupos étnicos evidenciou a diversidade linguística e cultural da região. Isso também pode ser visto a partir da cartografia feita pelo etnólogo Curt Nimuendaju que elaborou um mapa indicando a presença dos grupos indígenas e suas respectivas famílias linguísticas. Como mostra a Figura 1.

Figura 1: Diversidade etnolinguística no Amapá

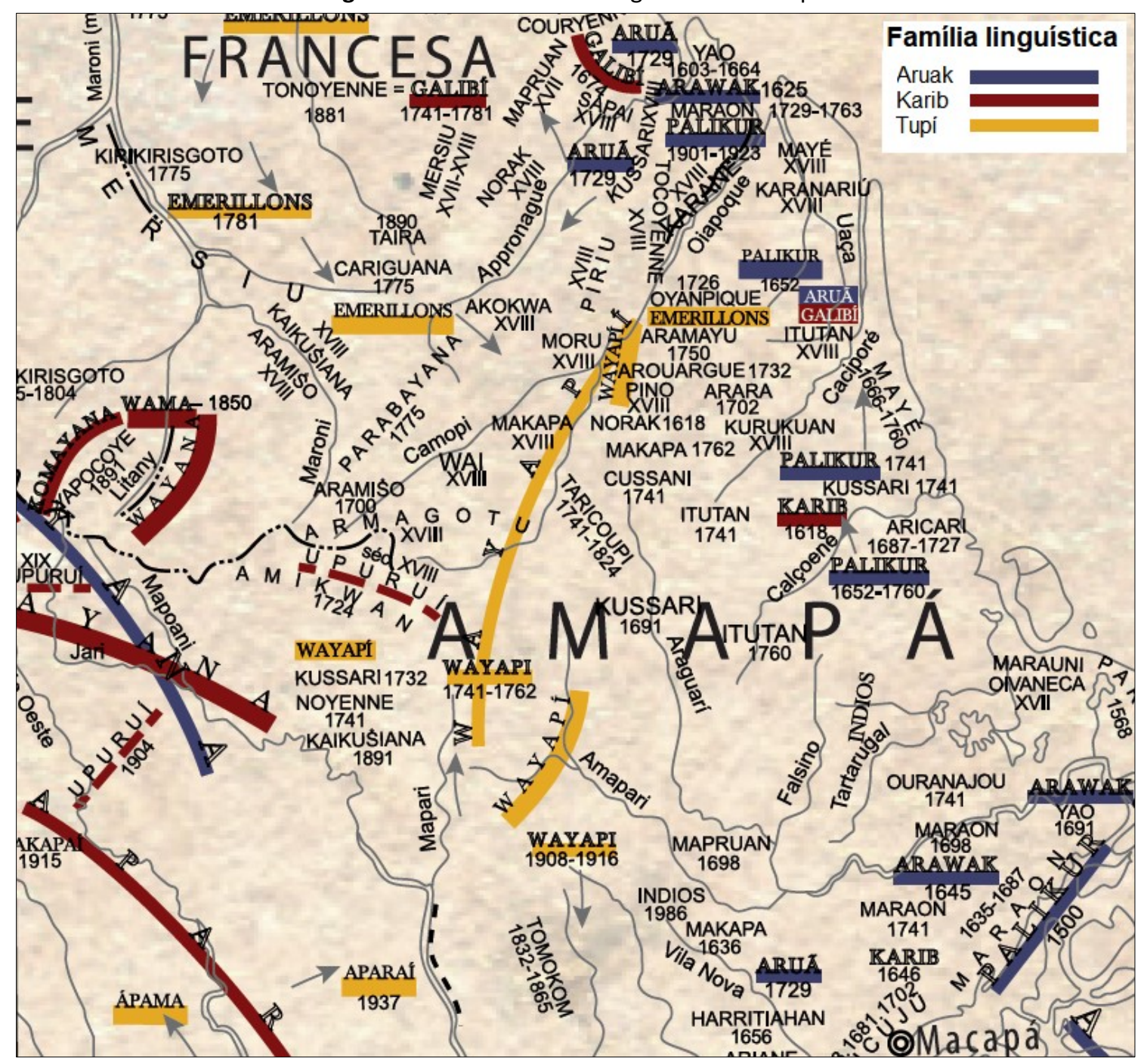

Fonte: Nimuendajú (2017). Adaptado pelo autor.

No que diz respeito ao presente século, os povos indígenas da região do Oiapoque somam mais de 7mil indígenas fixados em 50 aldeias localizadas às margens dos Rios Uaçá, Urukawá, Curipi, Oiapoque e de seus afluentes ${ }^{4}$. Na região do Oiapoque, há três Terras Indígenas (TI) demarcadas e homologadas pela Fundação Nacional do Índio - FUNAI: TI Uaçá, TI Galibi e TI Juminã. Nelas residem quatro etnias diferentes: Karipuna, Palikur, Galibi-Marworno e Galibi Kali'nã ${ }^{5}$.

\footnotetext{
${ }^{4}$ Os dados foram disponibilizados pela Coordenação Regional Amapá e Norte do Pará (CRANP) e tiveram sua última atualização em 2015.

${ }^{5}$ Os Palikur são um povo da família linguística Aruák; os Galibi-Kali'nã são falantes da família linguística Karib; os Galibi-
} 
Figura 2: Terras Indígenas Uaçá, Galibi e Juminã

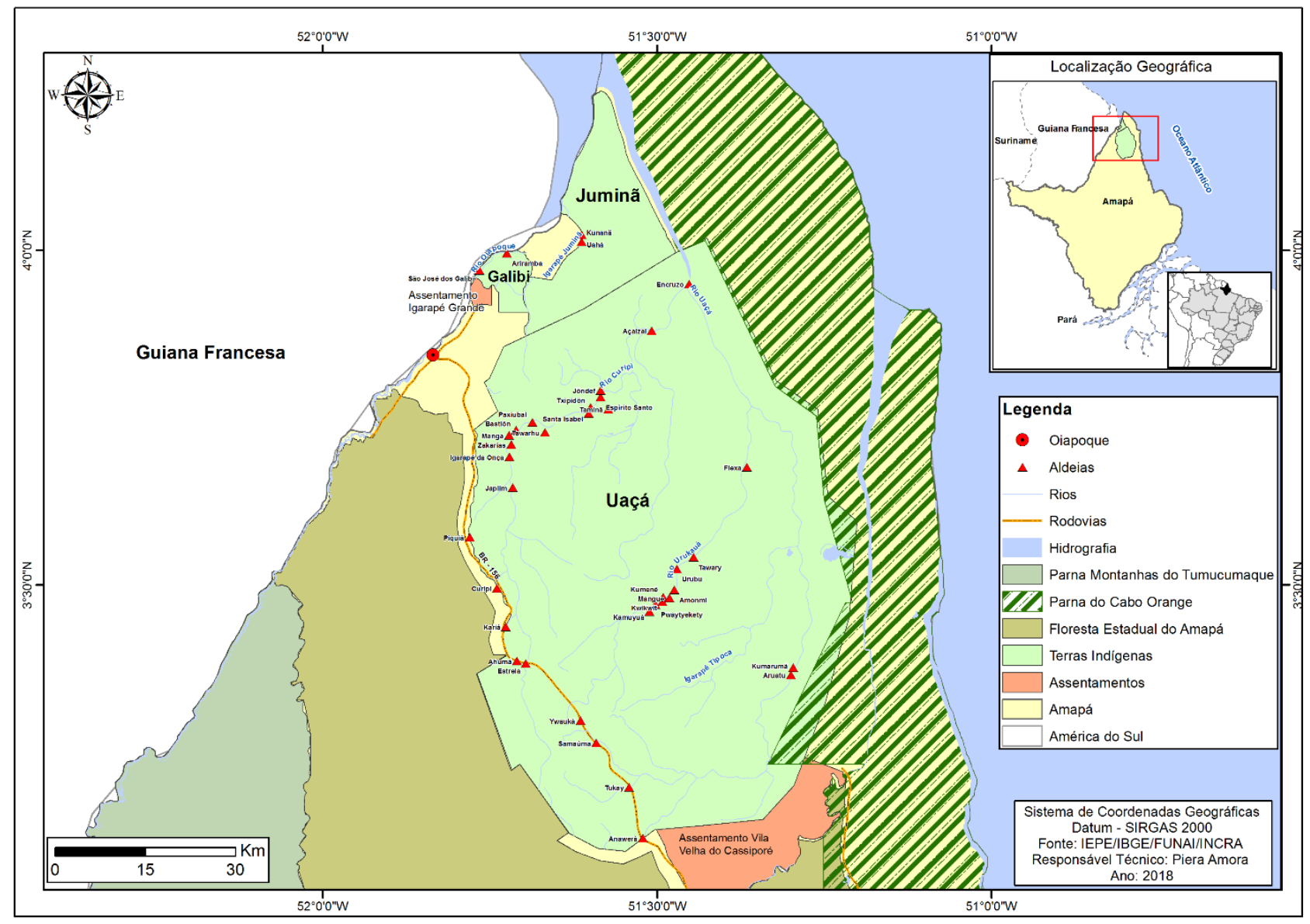

Fonte: Elaborado pelo autor.

Na Figura 2, é possível verificar a diversidade étnica da região por Terra Indígena - TI. A TI Galibi conta com uma superfície de 6.889/ha, sendo a primeira homologada, em 22 de novembro de 1982. A TI Uaçá apresenta uma superfície de 470.164 /ha, sendo homologada em 30 de outubro de 1991. E, por último, a TI Juminã, com uma superfície de 41.601/ha, homologada em 22 de maio de 1992.

Na Terra Indígena Uaçá, concentra-se o maior número de famílias indígenas, distribuídas ao longo da BR-156, à margem dos Rios Curipi, Urukawá e Uaçá. Na BR-156 estão localizadas as aldeias Yawauká, Kuahi, Estrela, Ahumã, Curipi, Piquiá, Kariá, Tukay, Samauma, Tuluhí e Anuerá. Nessas aldeias, há a presença de três etnias: Palikur, Karipuna e Galibi-Marworno. A população total na BR 156 está estimada em 687 indígenas.

No que tange às aldeias localizadas à margem do Rio Curipi, estão fixadas somente as aldeias da etnia Karipuna: Manga, Espírito Santo, Santa Isabel, Açaizal, Taminã, Cutiti/Jõdef, Japiim, Txibidon, Paxiubal, Benoá, Zacarias, Bastion, Encruzo, Pakapuá e Igarapé da Onça, com uma população total de 2.490 pessoas.

Ainda na TI Uaçá, nas aldeias da etnia Palikur, localizadas ao longo do Rio Urukawá, estão: Kumenê, Kamuyuwá, Flecha, Amomim, Pywatyket, Tawary, Kuwikuwit, Khobo, Mangue-i, Tipoca, Yanawá. Todas estas somam cerca 1.500 indígenas.

Marworno e os Karipuna são descendentes de vários grupos linguísticos, considerados falantes de línguas crioulas (MOORE, 2011, p. 228). 
Finalizando a TI Uaçá, no leito do rio que dá o nome à área indígena (Rio Uaçá), concentramse os indígenas da etnia Galibi-Marworno, as aldeias: Kumarumã, Aruatú, Paraikô, Paramwaká, Flamã, Karibuene, Kaxiuahi, Tucuiuí e Magí. Até o momento, a população soma 2.119 indígenas, mas esse número aumentará assim que atualizado o banco de dados referente ao quantitativo populacional das demais aldeias.

A TI Galibi, compreende duas aldeias: a aldeia Ariramba, pertencente à etnia Karipuna e a aldeia Galibi do Oiapoque, da etnia Galibi Kali'nã, localizadas no curso do Rio Oiapoque, com um total de 168 indígenas.

Por último, tem-se a TI Juminã, com as aldeias Kunanã e Uahá, localizadas no Igarapé Juminã. A primeira pertence ao grupo Karipuna e, a segunda, ao grupo Galibi-Marworno. Somam um total de 179 indígenas.

\section{Os Karipuna do Amapá}

A história do povo Karipuna é datada a partir do século XVII até os dias atuais. Tassinari (2003) é a principal referência no que diz respeito ao levantamento historiográfico e etnográfico desta etnia. A autora descreve a história dos Karipuna com base no etnônimo, afirmando que a primeira citação ao termo Karipuna foi registrada no século XVII, em Mocquet, com menção aos Caripous, citados como inimigos dos Caribes. Nas fontes dos viajantes D’Avity, Biet, Pfeil e La Barre também há referência aos dados de Mocquet sobre os Caripous, no entanto, sugerem associações confusas deste povo a outros grupos, ora os tratando como Caribes, ora como Palicours ou Yaos.

No século XVIII, Chabrillan cita os Cachipoux, localizados na região do baixo Oiapoque. Barrère e Lescallier mencionam os Calipourns. No século XIX, na mesma região, Léprier encontra famílias Garipons e Devilly comenta sobre os Calipournes (VIDAL; GIANNINI, 2005).

No século XX, o uso do nome Karipuna aparece nos textos de Nimuendajú e nos relatórios de Expedições de Fronteiras. Neste contexto, o termo passa a ser usado para diferenciar os povos nativos, bem como para expressar o sinônimo de uma língua geral usada na região ou, até mesmo, para designar "os brasileiros".

Observa-se que no percurso da história, famílias bastante heterogêneas começaram a se fixar na região. São pessoas de procedência indígena e não indígena que no decorrer da primeira metade do século XX foram identificadas como integrantes do grupo Karipuna6.

Com base nessa breve historiografia levantada, percebe-se que o termo Karipuna assume o caráter de etnônimo, topônimo e até sinônimo de Língua Geral. Essas imprecisões levaram Vidal (1998) a considerar o termo Karipuna como uma designação de alteridade, fazendo referência substantiva, designando uma determinada população ${ }^{7}$. É com base nessa ideia de alteridade que Tassinari (2003) defende que a gênese desse povo não é homogênea como foi cogitada, mas parte de princípios heterogêneos, entrelaçados pelos antepassados de outros povos autóctones e não somente de refugiados da Cabanagem falantes da Língua Geral.

\footnotetext{
${ }^{6}$ Como consta nos relatórios da Comissão de Inspeção de Fronteiras do Ministério de Guerra (CIFMG), comanda pelo General Rondon (1927).

7 Enquanto termo de alteridade, Karipuna foi empregado para designar tanto os "brancos", e mais precisamente, os brasileiros, pelos índios, quanto os índios pelos brasileiros e demais não índios.
} 
Atualmente, o termo Karipuna é usado como autodenominação por essa população e indica uma identidade de "índios misturados", "civilizados" ou "avançados". Nesse sentido, a noção de "mistura", expressa pelas famílias, refere-se à sua origem heterogênea, bem como às constantes alianças que estabelecem com indivíduos ou famílias estrangeiras (TASSINARI, 2003, p. 16).

De modo recente, a população indígena Karipuna do Amapá registra em torno de 2.991 indígenas, distribuídos em 22 aldeias, estando a maioria delas localizada na TI Uaçá, ao longo Rio Curipi. Há também cinco aldeias fixadas na BR-156, que liga a cidade de Macapá ao município de Oiapoque, além de uma aldeia no Rio Oiapoque, TI Galibi e mais uma no Igarapé Juminã ${ }^{8}$, na TI Juminã.

As aldeias Karipuna são nomeadas da seguinte forma: Manga, Espírito Santo, Santa Isabel, Açaizal, Kunanã, Ariramba, Taminã, Estrela, Ahumã, Cutiti/Jõdef, Curipi, Japiim, Piquiá, Kariá, Txibidon, Paxiubal, Benoá, Zacarias, Bastion, Encruzo, Pakapuá e Igarapé da Onça. As aldeias Manga, Espírito Santo e Santa Isabel concentram o maior número de famílias, com destaque para aldeia Manga que registra mais de 1.000 indígenas com residência fixa. Abaixo o Quadro 3 apresenta o nome das aldeias, sua localização, Terra Indígena e número populacional.

Quadro 3: População indígena Karipuna do Amapá

\begin{tabular}{|c|c|c|c|}
\hline ALDEIA & LOCALIZAÇÃO & TERRA INDÍGENA & POPULAÇÃO \\
\hline 1. Manga & Rio Curipi & Uaçá & 1014 \\
\hline 2. Espírito Santo & Rio Curipi & Uaçá & 602 \\
\hline 3. Santa Isabel & Rio Curipi & Uaçá & 371 \\
\hline 4. Açaizal & Rio Curipi & Uaçá & 118 \\
\hline 5. Kunanã & Igarapé Juminã & Juminã & 96 \\
\hline 6. Ariramba & Rio Oiapoque & Galibi & 88 \\
\hline 7. Taminã & Rio Curipi & Uaçá & 87 \\
\hline 8. Estrela & BR 156 & Uaçá & 80 \\
\hline 9. Ahumã & BR 156 & Uaçá & 78 \\
\hline 10. Cutiti/Jõdef & Rio Curipi & Uaçá & 65 \\
\hline 11. Curipi & BR 156 & Uaçá & 64 \\
\hline 12. Japiim & Rio Curipi & Uaçá & 60 \\
\hline 13. Piquiá & BR 156 & Uaçá & 48 \\
\hline 14. Kariá & BR 156 & Uaçá & 47 \\
\hline 15. Txibidon & Rio Curipi & Uaçá & 43 \\
\hline 16. Paxiubal & Rio Curipi & Uaçá & 39 \\
\hline 17. Benoá & Rio Curipi & Uaçá & 30 \\
\hline 18. Zacarias & Rio Curipi & Uaçá & 21 \\
\hline 19. Bastion & Rio Curipi & Uaçá & 12 \\
\hline 20. Encruzo & Rio Curipi & Uaçá & 12 \\
\hline 21. Pakapuá & Rio Curipi & Uaçá & 10 \\
\hline 22. Igarapé da Onça & Rio Curipi & Uaçá & 6 \\
\hline \multicolumn{3}{|c|}{$\begin{array}{lc} & \text { TOTAL } \\
\end{array}$} & 2.991 \\
\hline
\end{tabular}

Fonte: Elaborado pelo autor.

\footnotetext{
${ }^{8}$ Afluente do rio Oiapoque.
} 
Em relação à formação dessas aldeias, afirma-se que originalmente prevalecia o aspecto endógamo dos Karipuna, justificado pela convivência entre parentes e de grupos de irmãos que constituíam novas aldeias em lugares mais afastados da região. Foi assim que nos anos de 1940 as aldeias Açaizal e Santa Isabel foram criadas e, mais tarde, nos anos 1970, a aldeia Manga (VIDAL; GIANNINI, 2005).

Entre os anos de 1990 até os dias atuais tem-se a fundação de aldeias localizadas na BR-156, bem como, as fixadas ao longo do Rio Curipi. A tendência é de que novas aldeias recebam cônjuges provenientes de grupos locais, atraindo as famílias de origem para a nova aldeia; do contrário, essas pequenas comunidades podem desaparecer. Normalmente, o chefe da aldeia delimita um número de moradores para manter o controle demográfico do local, como no caso da aldeia Manga, que hoje conta com 1014 moradores indígenas.

\section{Motivações toponímicas para nomear aldeias do povo Karipuna do Amapá}

Para entender as motivações toponímicas implicadas no ato de nomear aldeias Karipuna é preciso entender também a história de fundação dessas localidades. Partindo dessa premissa será apresentada inicialmente uma breve história das aldeias Karipuna, baseadas em narrativas orais contadas pelos moradores indígenas. E posteriormente será apresentada a classificação toponímica para os respectivos nomes selecionados para análise.

Vale ressaltar que os dados analisados aqui correspondem a um recorte do projeto de pesquisa "Atlas Linguístico dos Karipuna do Amapá" que contou com coleta de campo realizada em nove aldeias Karipuna: Manga, Santa Isabel, Espírito Santo, Açaizal, Curipi, Kariá, Ahumã, Ariramba e Kunanã. Para cada aldeia foram entrevistados quatros indígenas, totalizando 36 colaboradores.

Para ilustrar as aldeias pesquisadas e selecionadas, segue a Figura 3 que destaca a localização de cada uma. 
Figura 3: Aldeias pesquisadas

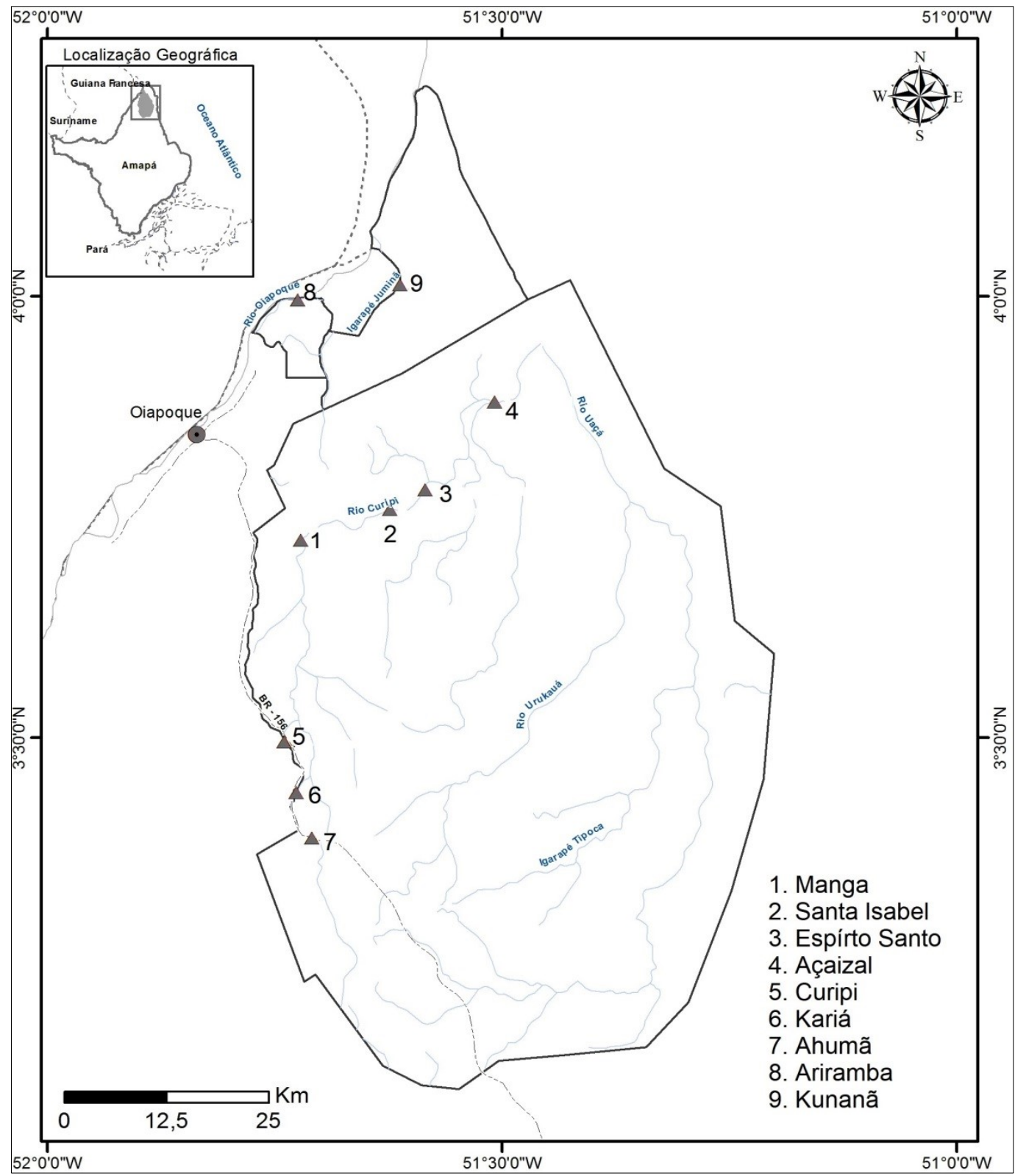

Fonte: Elaborado pelo autor.

A aldeia Manga (1) foi formada na década de 1970 e tem sua origem contada a partir do ingresso da família do Sr. Florêncio Primo dos Santos na região do Oiapoque. Nos relatos de N1, N2, $\mathrm{N3}^{9}$, as aldeias Santa Isabel e Espírito Santo são descritas como as mais povoadas. O inchaço populacional das referidas aldeias motivou a família do Sr. Florêncio a deixar a aldeia Santa Isabel em busca de um novo local. Assim, ele abriu uma roça no local onde se situa a atual aldeia Manga. Com ele vieram outras famílias, como a do Sr. Henrique, que logo se fixou, abrindo roças e construindo os kahbês, espécie de casa coberta de palha onde se produz farinha de mandioca. $O$ nome da aldeia foi dado devido à quantidade de mangueiras que existiam no local, por isso, aldeia Manga.

\footnotetext{
${ }^{9}$ A convenção diz respeito ao perfil do narrador que relatou a história da aldeia: N1: Homem jovem, N2: Mulher jovem, N3: Homem idoso e N4: Mulher idosa.
} 
A aldeia Santa Isabel (2), antes conhecida pelo nome de capoeira ou barracão ${ }^{10}$, tem sua fundação em meados da década de 1940, por Manuel Primos dos Santos, conhecido como Sr. Côco, responsável por construir uma casa de dois andares para sua família, uma parte feita de madeira e outra de tijolos. A criação de gado e a abertura de um comércio na aldeia atraíram novas famílias, iniciando o povoamento da localidade. Sobre o nome dado ao local, Dona Alexandrina ${ }^{11}$ conta que isso se deu como uma forma de pagar uma promessa, feita pelo Sr. Côco, ao Divino Espírito Santo e à Santa Isabel (padroeira da comunidade). Dona Alexandrina relata que quando Sr. Côco chegou ao local, ele não tinha condições financeiras de criar os filhos, de modo que os dois primeiros morreram. Então, o Sr. Côco fez uma promessa à Santa Isabel, pedindo pela vida de seus próximos filhos. E isso aconteceu, segundo os relatos, a terceira filha nasceu em uma ocasião na qual o Sr. Côco já tinha certa estabilidade financeira, o suficiente para criar a filha sem que ela viesse a óbito. Diante do fato, ele batizou a filha de Isabel e a comunidade de Santa Isabel, como forma de agradecimento pela graça alcançada.

A aldeia Espírito Santo (3) teve sua formação com a presença da família de João Teodoro Forte e, posteriormente, com os irmãos Firmino dos Santos e Cassiano dos Santos, ambos naturais da região de Vigia (PA), das cidades de São Caetano de Odivelas e de Mujuim. Mediante as narrativas, N3 e N4 comentam que a primeira aldeia fundada naquela região foi a aldeia Jõdef, conhecida como Cutiti. Segundo os indígenas, devido a uma epidemia de febre amarela na comunidade, os moradores foram obrigados a se mudar para a aldeia do Espírito Santo ${ }^{12}$. Esta localidade foi habitada inicialmente por um senhor, de descendência francesa, que cultivava laranjas. Em função da grande quantidade de laranjeiras presentes no sítio, a aldeia passou a ser conhecida como Laranjal. O nome atual é Espírito Santo, dado em decorrência da chegada de um padre que se instalou na comunidade para evangelizar. O padre carregava em mãos uma imagem do Divino Espírito Santo, que foi adotado como santo padroeiro do local.

A aldeia Açaizal (4) foi aberta em 1940 pelo Sr. Sebastião (Sabá) e sua esposa, Maria Frozina. Segundo consta nos relatos de N3 e N4, a aldeia tem sua origem associada à história do Sr. Sebastião que morava no Karipurá. Ao transitar pela aldeia Açaizal, durante atividade de caça e pesca, ele se deparou com um espaço agradável e resolveu abrir uma roça no local, em seguida, fixou residência. Aos poucos, novas famílias foram povoando a aldeia, cujo nome faz jus à árvore frutífera muito comum no local, o açazeiro.

A história da aldeia Curipi está relacionada à abertura e à pavimentação da BR-156. De acordo com os relatos de N1, N2 e N3, a FUNAl convidou a família de Dona Verônica, que morava na aldeia Manga, para ocupar a região da BR-156, pois era necessário resguardar o local contra a caça e a pesca irregular, além da retirada ilegal de madeira. A família de Dona Verônica mudou-se então para a localidade, próxima à atual aldeia Curipi. Os integrantes de sua família abriram um roçado e construíram um karbê. Com o passar do tempo, os filhos de Dona Verônica cresceram e constituíram famílias, construindo novas casas e abrindo novos roçados. Foi dessa forma que a aldeia passou a ser ocupada. Em 2005, a FUNAl informou que a aldeia não podia ficar próxima à

\footnotetext{
${ }^{10}$ Segundo Tassinari (2003, p. 180) barracão era uma velha habitação de um garimpeiro crioulo.

${ }^{11}$ Dona Alexandrina foi a segunda esposa do Sr. Côco.

12 Há outras versões para a origem da aldeia Espírito Santo como relatado por Tassinari (2003).
} 
rodovia, recomendando que a comunidade que ali vivia migrasse para um local mais afastado. Esse remanejamento ficou sob a responsabilidade do Governo Federal. O deslocamento levou em torno de 12 anos, até que as novas casas fossem construídas. Sobre o nome Curipi, N4 relatou que o "verdadeiro" nome da aldeia era Estrela, devido ao nome da montanha e do igarapé existentes na localidade. No entanto, o Sr. Henrique, à época, chefe de posto da FUNAI, já havia dado o mesmo nome, Estrela, à outra aldeia, fundada no ano de 1981, localizada a $70 \mathrm{~km}$ do Oiapoque. Então, optou-se pelo nome Curipi, fazendo referência ao rio que passa próximo a aldeia Estrela, no kilomêtro 70.

A aldeia Kariá também segue o mesmo processo de ocupação da aldeia Curipi. Conforme relato de N1 e N3, os primeiros moradores do Kariá eram provenientes da aldeia Manga. Segundo consta em convite feito pela FUNAl, os senhores Manuel João dos Santos e Henrique dos Santos passaram a ocupar a BR-156, exercendo cargos da FUNAI no posto de vigilância da aldeia Estrela. Com o passar dos anos, Manuel João dos Santos que morava na aldeia Piquiá, aberta em 1990, pela família do Pajé Raimundo e de Dona Filomena Fortes, decidiu fundar sua própria aldeia, a fim de abrigar seus filhos e parentes. O nome dado a aldeia faz menção à grande quantidade de espécie de cerrado conhecido como Kariá.

A criação da aldeia Ahumã tem sua origem remetida às realizações pessoais da Cacique Creuza Maria dos Santos. Os filhos da Cacique, N1 e N2, relatam a história da mãe como uma mulher guerreira, de personalidade forte e que serve de inspiração para os demais membros da família. Eles lembram que a mãe morava na aldeia Estrela, mas os conflitos familiares fizeram com que ela buscasse um novo local. A aldeia tem cerca de 20 anos de criação. A atual área onde se estabeleceu a família da Cacique fica localizada na BR-156, a $60 \mathrm{~km}$ de Oiapoque. No início, ela e seus filhos tinham apenas uma roça e um karbê no local, abrigando todos os membros da família. Na medida em que os filhos foram casando, novas casas foram erguidas, e as roças se multiplicaram. O nome Ahumã diz respeito a um tipo de planta característica da área ocupada.

A aldeia Ariramba tem sua data de fundação em 1940, sob a responsabilidade do Sr. Filinto, ex-funcionário do Serviço de Proteção ao Índio (SPI) que trabalhava no posto da FUNAI na aldeia Galibi, casado com Dona Trindade Forte. Os relatos de N1, N2 e N4 constatam que antes de habitarem a aldeia Ariramba, o Sr. Filinto e sua família buscavam abrigo na vila Taparabô. Em uma das viagens pelo Rio Oiapoque, ele se agradou da atual área onde está fixada a aldeia e, em seguida, decidiu mudar-se para lá com a sua esposa e os seus filhos. Eles abriram roças e plantaram laranjas, tangerinas, bananas, etc. Os filhos de Sr. Felinto constituíram famílias, em que cada um tornou-se responsável pela construção de suas casas e, assim, a aldeia ganhou novos moradores. N3 relata que, quando chegou ao local, a área era frequentada por um tipo de pássaro pescador, conhecido como Ariramba, por este motivo a aldeia passou a se chamar Ariramba.

A aldeia Kunanã foi fundada por Gabriel dos Anjos ${ }^{13}$. Segundo o relato de N2, seus avós contam que o Sr. Gabriel morava sozinho com a sua esposa. Dono de um sítio, o Sr. Gabriel criava galinhas e outros animais. Alguns amigos e familiares do Sr. Gabriel sempre vinham da aldeia Espírito Santo visitá-lo. Com o tempo, ele adoeceu, ficando sob os cuidados de amigos e parentes de outras aldeias que ali se fixaram. Com o falecimento do Sr. Gabriel dos Anjos, outras famílias foram

\footnotetext{
${ }^{13}$ Não há uma data precisa de fundação, mas cogita-se que a aldeia deva ter mais de 40 anos.
} 
chegando e habitando o local. O primeiro nome da aldeia foi Juminã ${ }^{14}$, mas como a FUNAI usou o mesmo nome para oficializar a Terra Indígena, a comunidade escolheu o nome Kunanã, em decorrência da existência de uma fruta silvestre cultivada naquela região.

Diante desse levantamento histórico sobre a criação das aldeias pesquisadas, há dois fatores preponderantes que motivaram o surgimento das aldeias. O primeiro, o desejo pessoal dos próprios indígenas em ter a sua própria aldeia, evitando conflitos entre familiares. O segundo, motivado pelo convite feito aos indígenas por parte da FUNAI, no sentido de ocupar áreas desprotegidas nos arredores dos postos de vigilância da área indígena.

Constatou-se também que as motivações para nomear as aldeias estão relacionadas, predominantemente, aos aspectos da fauna e da flora característicos de cada localidade. Nesse sentido foi possível identificar e classificar os topônimos usados para nomear aldeias da seguinte maneira, conforme Quadro 4.

Quadro 4: Taxionomias das aldeias dos Karipuna do Amapá

\begin{tabular}{|c|c|c|}
\hline Nome da aldeia & Tipo & Conceito \\
\hline Manga & Fitotopônomos & Topônimos relativos aos vegetais; \\
\hline Espírito Santo & Hierotopônimos & Topônimos relativos a nomes sagrados de crenças religiosas; \\
\hline Santa Isabel & Hierotopônimos & Topônimos relativos a nomes sagrados de crenças religiosas; \\
\hline Açaizal & Fitotopônomos & Topônimos relativos aos vegetais; \\
\hline Curipi & Hidrotopônimos & Topônimos relativos a acidentes hidrográficos em geral; \\
\hline Kariá & Fitotopônomos & Topônimos relativos aos vegetais; \\
\hline Ahumã & Fitotopônomos & Topônimos relativos aos vegetais; \\
\hline Ariramba & Zootopônimos & Topônimos referentes aos animais; \\
\hline Kunanã & Fitotopônomos & Topônimos relativos aos vegetais; \\
\hline
\end{tabular}

Fonte: Elaborado pelo autor.

A maioria dos topônimos é do tipo fitotopônomos, isto é, que fazem referência a vegetais como Manga (fruta), Açaizal (planta), Kariá (planta) e Kunanã (fruta). Há também dois topônimos do tipo hierotopônimos que fazem referência a nomes sagrados como Espírito Santo e Santa Isabel. Um topônimo do tipo hidrotopônimo que faz referência a acidentes hidrográficos como Curipi (nome de rio). E por último, o do tipo zootopônimo que faz referência a animais como Ariramba (nome de uma espécie de pássaro).

\section{Considerações finais}

Os resultados desta pesquisa mostraram que as principais motivações para nomear as aldeias são de natureza física, do tipo fitotopônimos (Manga, Açaizal, Kariá, Ahumã e Kunanã), hidrotopônimos (Curipi) e zootopônimos (Ariramba). E em menor grau de motivação, registraram-se também os de natureza antropo-cultural, é o caso dos hierotopônimos (Santa Isabel e Espírito Santo).

Ainda com base nos resultados é possível identificar a procedência dos nomes. Os topônimos Manga, Espírito Santo, Santa Isabel e Açaizal são usados em Português, já os topônimos Curipi, Kariá, Ahumã, Ariramba e Kunanã são usados em Kheuól.

\footnotetext{
${ }^{14} \mathrm{O}$ mesmo nome do Igarapé Juminã, afluente do Rio Oiapoque.
} 
Por ser um estudo inicial e talvez o primeiro dessa natureza a ser feito no Amapá, é certo que ainda requer aprofundamento teórico e uma análise mais ampliada dos dados como a inclusão dos nomes das demais aldeias Karipuna, tendo em vista que nesse primeiro momento foram analisados apenas nove topônimos.

A partir deste trabalho, pode-se pensar em estudos posteriores, como analisar topônimos para os nomes de aldeias das etnias Wajãpi, Galibi Marworno, Galibi Kali'nã e Palikur. O objetivo seria confirmar se a predominância de topônimos de natureza física, encontrados nos nomes das aldeias Karipuna, também predominarão nos demais grupos indígenas, dado às circunstancias socioculturais e ecológicas em que estes grupos se encontram.

\section{Referências}

BIDERMAN, M. T. C. As ciências do léxico. In: OLIVEIRA, A. M. P. P; ISQUERDO, A. N. (Orgs.). As ciências do léxico: lexicologia, lexicografia, terminologia. v. 1. Campo Grande: Ed. UFMS, 2001. p. 153-166.

BIDERMAN, M. T. C. O Léxico: testemunha de uma cultura. In: Actas do XIX Congresso Internacional de Linguistica e Filoloxia Rómanias, sessão II: Lexicologia e Metalexicografia, vol. 1992. P. 397-405.

D'AVITY, P. Description generale de L'Amerique troisesme partie du monde avec tovs ses empires, royavmes estats et republiques. Paris: Laurent Cottereav, 1643.

DICK, M. Toponímia e Antroponímia no Brasil. Coletânea de estudos. 2. ed. São Paulo: Serviço de Artes Gráficas/FFLCH/USP, 1990.

HURAULT, J-M. Français et indiens em Guyane, 1604-1972. Paris: Union Générale d'Editions, 1972.

MELO, G. C. de. A língua do Brasil. 4. ed. Rio de Janeiro: Padrão, 1981.

MOCQUET, J. Voyages em Afrique, Asie, Indies orientales e occidentales. Paris: Jean de Hierquevieu, 1617.

MOORE, D. Línguas indígenas. In: MELLO, H.; ALTENHOFEN, C.; RASO, T. Os contatos linguísticos no Brasil. Belo Horizonte: UFMG, 2011, p. 217-240.

NIMUENDAJÚ, C. Mapa etno-histórico e regiões adjacentes. Brasília: IPHAN, IBGE, 2017.

PARANHOS, J. M. S. Obras do Barão do Rio Branco: questões de Limites. Rio de Janeiro, Ministério das Relações Exteriores. [vol. III: Guiana Francesa 1a Memória; vol. IV: 2ª Memória], 1945.

TASSINARI, A. M. I. No Bom da Festa: o processo de construção cultural das famílias Karipuna do Amapá. São Paulo: EDUSP, 2003.

TAVARES, M. C.; ISQUERDO, A. N. A questão da estrutura morfológica dos topônimos: um estudo na toponímia sul-mato-grossense. Revista Signum. Estudos de Linguagens, Londrina-PR, v. 9/2, p. 273-288, 2006.

VIDAL, L. Relatório de Andamento de Pesquisa para o Projeto Temático: Sociedades Indígenas e suas Fronteiras na Região Sudoeste das Guianas (mimeo). 1998.

VIDAL, L; GIANNINI, I. V. Estudo etnoecológico nas Terras Indígenas Uaçá, Galibi e Juminã. Relatório Preliminar, 2005. 